\title{
Prejudice and xenophobia in COVID-19 research manuscripts
}

To the Editor - Scholars and academic journals have rightly been concerned with the global health implications of the 2019 novel coronavirus (COVID-19) pandemic, but far less so with the simultaneous spread of prejudice and xenophobia. For example, US President Donald Trump has referred to severe acute respiratory syndrome coronavirus 2 (SARS-CoV-2) as the Chinese virus (https://abcnews.go.com/Politics/ chinas-ambassador-us-slams-trump-covid19-blame/story?id=72187153). Just as viruses can influence our brain and behaviour, so too can information. Unreliable information and collective perceptual bias has exacerbated fear, prejudice, and xenophobia ${ }^{1}$. Scholars are at the forefront of scientific research, with the potential to offer objective voices. Academic journals promote the dissemination of valuable knowledge and play a crucial role in controlling COVID-19. However, some academic journals, including some of the top medical journals, have ignored the fact that some of the content published in their pages may give rise to prejudice and xenophobia. Thousands of manuscripts related to COVID-19 have been published thus far. A search of PubMed (see Supplementary Table 1 for more detail) finds that over 2,000 manuscripts mention Wuhan in their abstract or introduction. Many of these manuscripts describe the COVID-19 pandemic as originating or beginning in Wuhan, China, in their abstract or introduction ${ }^{2}$. This is a careless and inaccurate statement.
If left unchecked, there could be more such inappropriate comments to come. COVID-19 pneumonia was first reported in Wuhan, Hubei Province, China, in December 2019. However, it is not certain that the origin was in Wuhan. In research reported in a non-peer-reviewed preprint, Spanish researchers tested a sample of local wastewater in Barcelona and found SARS-CoV-2 in the wastewater collected on 12 March last year, while Barcelona reported its first confirmed case of COVID-19 on 25 February this year ${ }^{3}$. Similarly, in research reported in a non-peer-reviewed preprint, Brazilian researchers found SARS-CoV-2 in sewer water samples taken last November in Florianopolis, the capital of the Brazilian state of Santa Catarina, much earlier than the first reported case in the Americas on January 21 (ref. $^{4}$ ).

Throughout history, viral diseases have often been associated with the places or regions where outbreaks first occurred. In 2015, the WHO introduced guidelines to stop this practice and thereby reduce prejudice and xenophobia directed towards those regions or their people (https:// www.who.int/topics/infectious_diseases/ naming-new-diseases/en/). The origin of COVID-19 is still a mystery that needs further study and confirmation. Without conclusive evidence, it is not appropriate to emphasize the unconfirmed origin of the SARS-CoV-2 virus in manuscripts. Continuing to associate a virus and the disease it causes with a specific place is irresponsible and needs to stop.
Scientific research should be rigorous, objective and do no harm, so we need to be careful about misleading comments in our research manuscripts. Authors, reviewers and editors should carefully watch for and remove any inappropriate comments. Our reports should not only show academic achievements and provide reference for other scholars, but also play a constructive role in communicating science to the general public. In the face of this human catastrophe, global solidarity is the answer, not alienating people through politicizing and mislabelling scientific issues ${ }^{5}$.

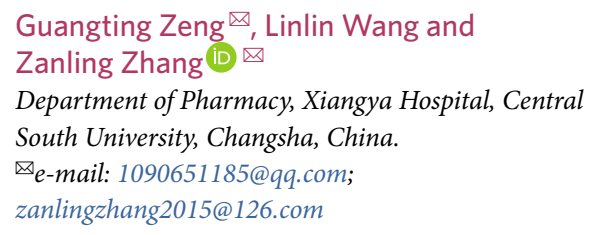

Published online: 21 August 2020 https://doi.org/10.1038/s41562-020-00948-y

References

1. Jakovljevic, M., Bjedov, S., Jaksic, N. \& Jakovljevic, I. Psychiatr. Danub. 32, 6-14 (2020).

2. Holshue, M. L. et al. N. Engl. J. Med. 382, 929-936 (2020).

3. Chavarria-Miró, G., et al. Preprint at medRxiv https://doi. org/10.1101/2020.06.13.20129627 (2020).

4. Fongaro, G., et al. Preprint at medRxiv https://doi. org/10.1101/2020.06.26.20140731 (2020).

5. Devakumar, D. et al. Lancet 395, el12-e113 (2020).

Competing interests

The authors declare no competing interests.

Additional information

is available for this paper at https://doi.org/10.1038/

s41562-020-00948-y. 